\title{
Response of the auroral electrojet indices to abrupt southward IMF turnings
}

\author{
J. W. Gjerloev ${ }^{1}$, R. A. Hoffman ${ }^{2}$, S. Ohtani ${ }^{1}$, J. Weygand ${ }^{3}$, and R. Barnes ${ }^{1}$ \\ ${ }^{1}$ Applied Physics Laboratory - Johns Hopkins University, Laurel, MD 20723, USA \\ ${ }^{2} 15107$ Interlachen Drive, \#714, Silver Spring, MD 20906, USA \\ ${ }^{3}$ Institute of Geophysics and Planetary Physics Department of Earth and Space Sciences, UCLA, CA, 90095, USA
}

Received: 24 November 2009 - Revised: 29 April 2010 - Accepted: 10 May 2010 - Published: 26 May 2010

\begin{abstract}
We present results from a study of the behavior of the auroral electrojet indices following abrupt southward turnings of the IMF $B_{\mathrm{z}}$. The auroral electrojet indices are calculated from observations made by more than 100 ground based stations provided by the SuperMAG collaborators. Based on three simple criteria we selected 73 events. In each event the interval of analysis started at the time of the IMF $B_{\mathrm{Z}}$ southward turning and ended 45 minutes later or at the onset of any abrupt energy unloading event in the magnetosphere, regardless of size. We refer to this period as the "pre-unloading phase". To isolate the dependence of the auroral electrojets on the solar induced ionospheric conductivity during this phase we separated the standard AU/AL indices into two new sets of indices defined by the upper and lower envelope of the north-south component for all sunlit stations (AUs/ALs) and for all stations in darkness (AUd/ALd). Based on events and statistical analyses we can conclude that following a southward turning of the IMF $B_{Z}$ the AUd/ALd indices show no measurable response while the AUs/ALs indices clearly intensify. The intensifications of AUs/ALs are dependent on the intensity of the solar wind driver (as measured by IMF $B_{\mathrm{Z}}$ or the Akasofu $\varepsilon$ parameter). The lack of AUd/ALd response does not depend on the intensity of any subsequent substorm.

We find that during these isolated events the ionospheric current system is primarily confined to the sunlit ionosphere. This truncated version of the classical global DP-2 current system suggests that auroral electrojet continuity is not maintained across the terminator. Because of its conductivity dependence on the solar zenith angle, this truncated global current pattern is expected to be highly dependent on UT and season and thus can be asymmetric between hemispheres.
\end{abstract}

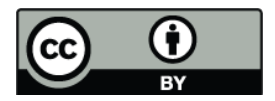

Correspondence to: J. W. Gjerloev (jesper.gjerloev@jhuapl.edu)
Thus we argue that the global two-cell DP-2 current system is not a consequence only of a southward turning of the IMF but requires also the reduction of the conductivity gradient at the terminator.

Keywords. Magnetospheric physics (Current systems; Magnetosphere-ionosphere interactions; Solar windmagnetosphere interactions)

\section{Introduction}

McPherron (1970) noted in his groundbreaking study that in addition to an expansion phase and a recovery phase, polar magnetic substorms had a growth phase prior to the expansion phase during which many magnetospheric phenomena occur. Since then many papers have addressed the response of the magnetosphere-ionosphere system to IMF southward turnings. It is generally accepted that the dawn and dusk auroral electrojets (westward and eastward, respectively) start to develop during this period indicating that these electrojets are primarily caused by enhancements of the ionospheric convection electric field associated with the southward turning of the IMF (e.g. Kamide and Vickrey, 1983).

Following a southward turning and preceding a substorm expansion phase onset the ionospheric current system is known as the DP-2 system (to avoid any confusion with the global two cell convection pattern we will refer to this as the DP-2 current system). Obayashi and Nishida (1968) illustrated the high latitude DP-2 currents with the primary characteristics of two current cells with maxima near dawn and dusk and a mostly sunward current across the polar cap (also see for example Nishida, 1971; Clauer and Kamide, 1985). Interestingly, in the original definition of the DP2 current system by Nishida (1968) he observed that the DP-2 currents "are not associated with the excitation of the

Published by Copernicus Publications on behalf of the European Geosciences Union. 
auroral electrojet" (p. 1802). Vasyliunas (1970), however, challenged this by showing that a current will flow in the auroral zone assuming enhanced ionospheric conductivity in this region.

Since the McPherron (1970) study it has been widely accepted that a gradual intensification of the eastward and westward auroral electrojets is associated with the growth phase. Typically the growth phase is defined as beginning at the time of the southward turning of the IMF $B_{\mathrm{Z}}$ (GSM, propagated to the dayside bow shock) and ending at the onset of the substorm expansion phase (e.g. Gjerloev et al., 2003). This period has been published to last some tens of minutes (for example 40 min Kamide and Kokubun, 1996; 60 min Iyemori, 1980; and 1-2 h Iijima and Nagata, 1972).

According to the two-component electrojet picture the electrojets are assumed to be directly driven by solar wind magnetosphere interactions such as merging and viscous effects. Baumjohann (1983) stated that "during the growth phase/convection bay the Hall current flow in the auroral electrojets increases in direct relation to the energy input from the solar wind into the magnetosphere" (p. 59). This statement is of fundamental importance to the global DP2 current picture and the two-component electrojet concept since it predicts a cause and effect. While the eastward and westward electrojets should respond simultaneously to changes in the IMF driver, any difference in the intensity of the two electrojet components can be attributed to differences in the conductivity and strength of the dawn and dusk convection electric field. Kamide and Kokubun (1996) illustrated the behavior of the auroral electrojets as measured by the $\mathrm{AU}$ and $\mathrm{AL}$ indices for two different IMF conditions. In their schematic illustration the AU and AL both start intensifying at the time of the IMF southward turning without any apparent delay. Further both indices show a gradual intensification until the onset of the expansion phase. Both these central points are in agreement with the Baumjohann (1983) statement above. The global DP-2 current system predicts eastward and westward auroral electrojets flowing across the terminators from the dayside to the nightside (e.g. Baumjohann, 1983) disregarding the presence of a conductivity gradient.

Despite this consistency in the literature, we have not encountered any careful analysis of the period immediately following the southward turning of the IMF when there is purely a directly driven system, i.e., before any abrupt magnetospheric energy unloading events changes the ionospheric conductivity pattern. In this paper we ask the basic question: what is the response of the ionospheric current system to an abrupt southward turning of the IMF $B_{\mathrm{z}}$ ? We perform an analysis using a solid observational basis consisting of data from more than 100 ground based magnetometers obtained during 73 events. We focus primarily on the so-called directly driven ionospheric current system and hence we terminate our analysis at the onset of any unloading of energy from the magnetosphere (e.g. a substorm).
In Sect. 2 we describe the data used; Sect. 3 provides definitions of our terminology; Sect. 4 shows two examples; in Sect. 5 we perform the statistical analysis of our selected events; in Sect. 6 we discuss how our results are related to the solar wind driver, substorms, and seasonal effects and what the implications are for the classical DP-2 current picture; and finally in Sect. 7 we summarize and draw conclusions.

\section{Data}

This study utilizes global ground-based magnetic field perturbations provided by the SuperMAG initiative (Gjerloev, 2009), and solar wind data obtained by the ACE spacecraft. Magnetic indices are calculated from all available stations located at magnetic latitudes of 50-80 deg, which typically includes 100-110 stations In agreement with the definition of the standard AL/AU indices we do not include polar cap stations (here loosely defined as latitudes above 80 deg magnetic latitude) since their perturbations are not associated with the auroral electrojets. Historically the indices have been interpreted as a monitor of the auroral electrojet activity and thereby of magnetospheric activity. Due to the popularity of the indices their limitations and interpretations have become an important issue (e.g. UT effects, Rostoker, 1972; Allen and Kroehl, 1975; Ahn et al., 2000, 2002). The limitations are primarily due to the small number of magnetometer stations normally used (10-12 stations) and their uneven spatial distribution thereby implying that large perturbations can go undetected if they are constrained in longitude or are located at latitudes poleward or equatorward of the AE station network. The 12 standard AE stations are located at latitudes between $60^{\circ}$ and $72^{\circ}$ but our much more complete spatial coverage minimizes the various caveats of the indices.

As we will show the ionospheric electric conductivity appears to be a key factor in controlling the electrojets, and hence we calculate the AU and the AL indices separately for sunlit stations and not sunlit stations. The terminator is defined at an altitude of $200 \mathrm{~km}$ for solar zenith angles of $104^{\circ}$. We refer to these indices as ALs (AL sunlight), ALd (AL darkness), AUs (AU sunlight) and AUd (AU darkness). That is the indices AUs and ALs are always defined by sunlit stations while AUd and ALd are always defined by not sunlit stations. Hence, the classical AU is defined as the larger value of AUs and AUd (likewise with AL). The classical AU/AL indices are deduced from only 12 ground based stations and the large gaps in the coverage result in various artifacts. With the introduction of the SuperMAG collaboration the coverage is vastly improved and the caveats are thus limited.

Events are selected using 3 criteria:

1. 45 min of uninterrupted northward IMF $B_{\mathrm{Z}}$ followed by 45 min of uninterrupted southward IMF; 

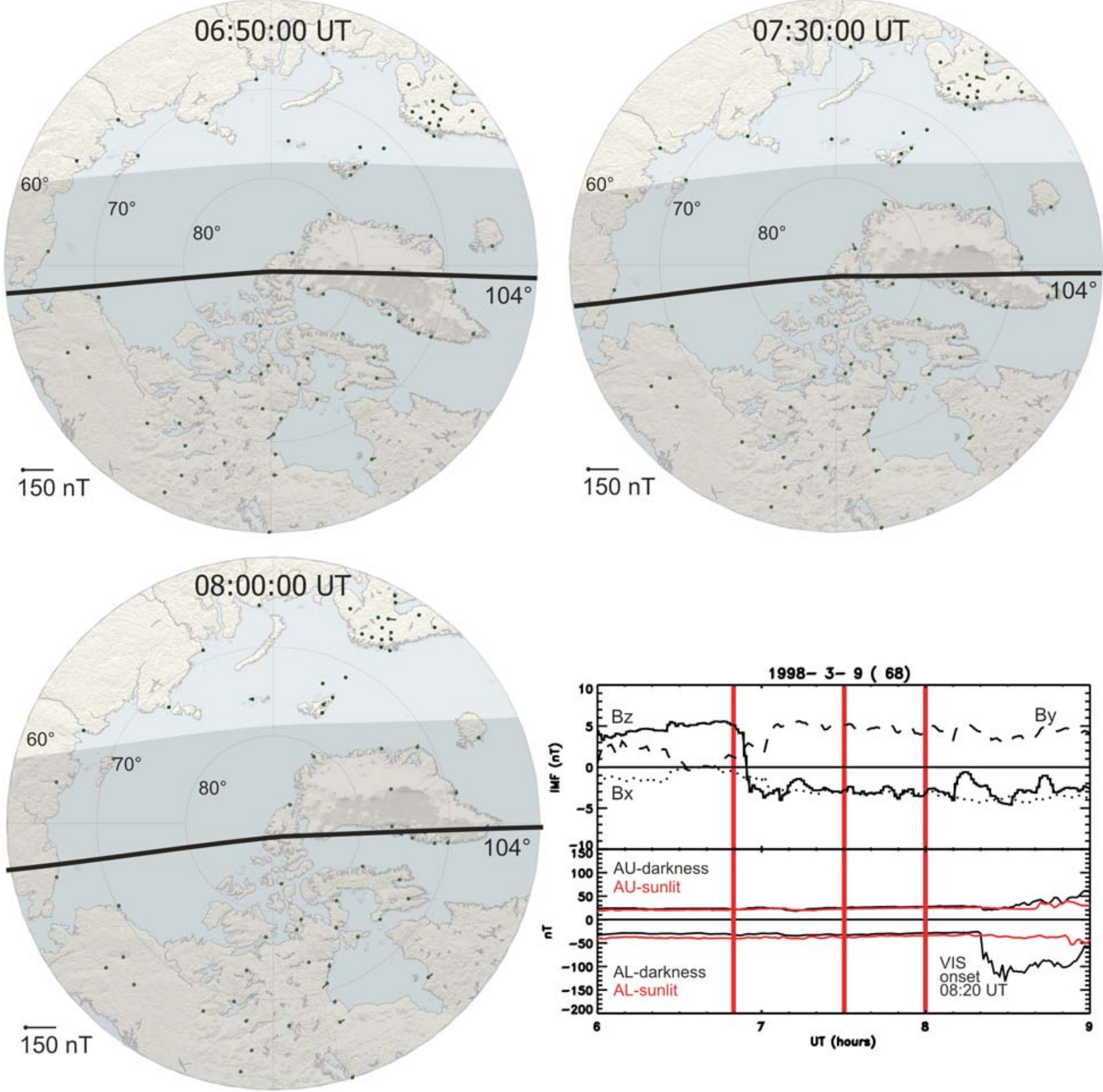

Fig. 1. A typical event from 9 March 1998 when most of the auroral region was in darkness. Superposed onto the polar plot are ground magnetic field vectors (units of nT) rotated $90^{\circ}$ clockwise to indicate the equivalent current direction. Both the $90^{\circ}$ and $104^{\circ}$ terminators are shown on the plot. The line plots show the three components of the propagated IMF and the AU/AL indices determined from sunlit stations (AUs/ALs) and stations in darkness (AUd/ALd). Vertical red lines indicate the time of the polar plots. Images obtained by the VIS Earth Camera carried on the Polar satellite show the onset of a weak substorm at 08:20 UT.

2. $|\mathrm{AL}|$ and $\mathrm{AU}<100 \mathrm{nT}$ for 45 min prior to southward turning;

3. Polar VIS Earth Camera images of the entire auroral oval throughout the $90 \mathrm{~min}$;
The purpose of these criteria is to isolate the response of the auroral electrojets only to southward turnings of the IMF $B_{\mathrm{Z}}$. The first criterion ensures that we only analyze intervals with clean indisputable transitions. We accept a \pm 5 min transition period during which the $B_{\mathrm{Z}}$ can fluctuate. The center 

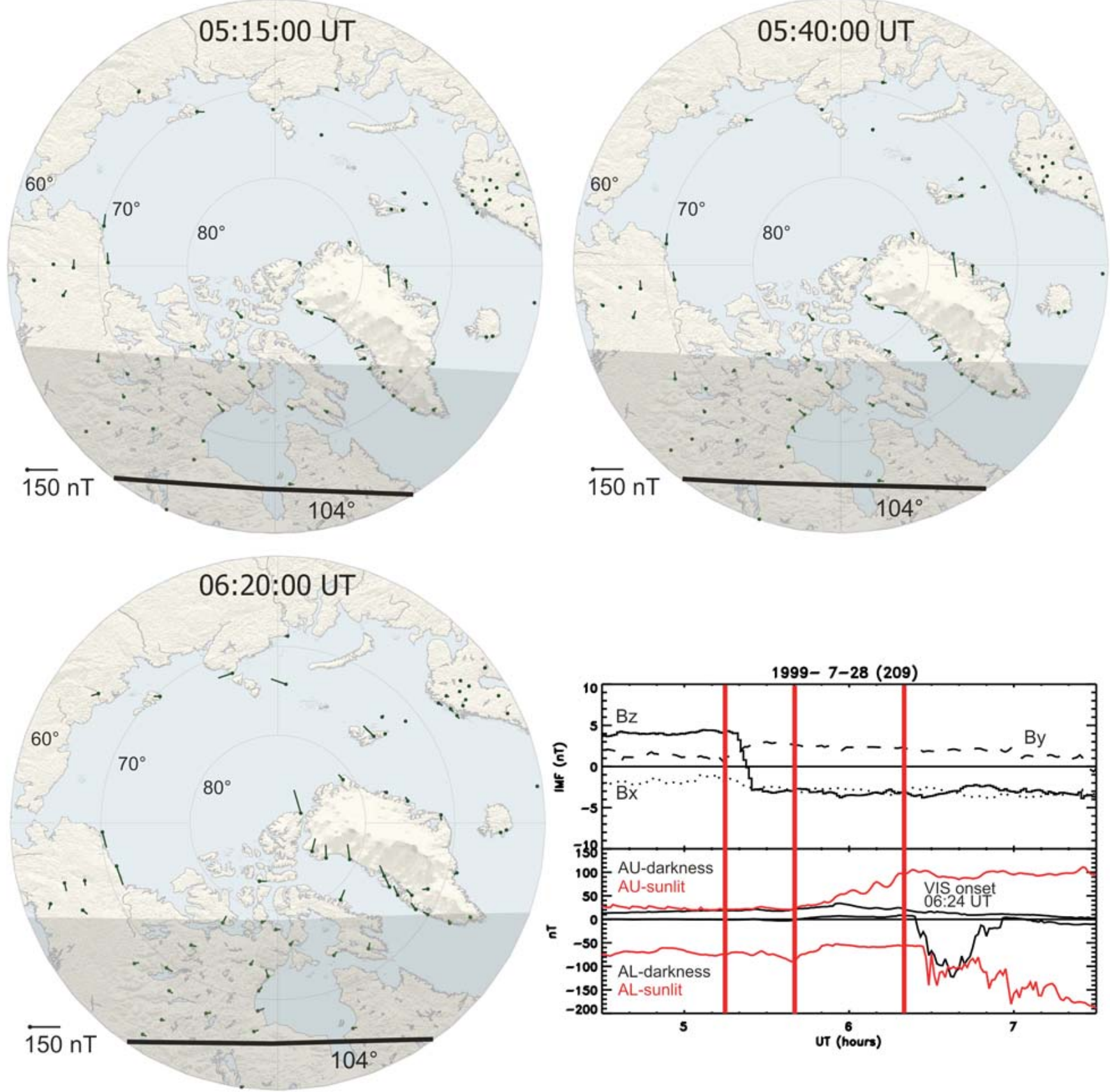

Fig. 2. A typical event from 28 July 1999 when most of the auroral region was sunlit. Same format as Fig. 1.

of the transition period is chosen to be the actual transition. It should be noted that the vast majority of the events have clear single point north-to-south transitions (see for example Figs. 1 and 2). The second and third criteria exclude recovery intervals of previous substorms or other explosive activity, which presumably were driven by processes internal to the magnetosphere and thus would obscure the process on which this paper is focusing. The third criterion also provides for a careful examination of images to ensure that unloading events occurring within $45 \mathrm{~min}$ of the southward turning are excluded. We do include the event but terminate the analysis at the onset of any explosive unloading features. Hence not all events provide a full $45 \mathrm{~min}$ of data following the southward turning though a majority do (56 of 73 provide a full $45 \mathrm{~min}$ ). We have focused on the years 1999-2001 when the ACE spacecraft monitored the solar wind conditions; when the Polar spacecraft provided extensive periods of uninterrupted imaging of the Northern Hemisphere; and when the 
SuperMAG data holdings could be utilized. Using these criteria we found 73 events that provide the basis for the analysis presented in this paper.

The solar wind data obtained by the ACE spacecraft have been propagated to the bow shock (17 $R_{\mathrm{E}}$ upstream) using the Weimer et al. (2003) method. Finally, as described above, we use Earth camera images acquired by the Visible Imaging System (VIS) on the Polar satellite (Frank et al., 1995). This camera provides global auroral images in the far ultraviolet (FUV) range of $\sim 124-149 \mathrm{~nm}$ in contrast to the more limited views but higher spatial resolution from its two visible imaging cameras.

\section{Terminology}

The growth phase is generally defined as the period starting at the southward turning of the IMF $B_{\mathrm{Z}}$ and ending at the substorm expansion phase onset. We maintain this term. We start our analysis at the southward turning but end it at the onset of any abrupt event involving the unloading of energy from the magnetosphere, or after $45 \mathrm{~min}$, whichever is sooner. Throughout the paper we will refer to this time period as the "pre-unloading phase", since it involves solely solar induced conductivity and electric field convection from the solar wind-magnetosphere interaction. This is consistent with the terminology used by Kamide and Kokubun (1996).

Besides substorm expansion, an abrupt unloading event can be a pseudo onset that classically will not be defined as the end of the growth phase. Thus we only analyze part of the period typically referred to as the growth phase. We do this since the purpose of the paper is to determine the response of the ionospheric currents to southward turnings of the IMF $B_{\mathrm{Z}}$. The introduction of any unloading event will contribute to intensifications of the AU/AL indices and hence eliminate any chance of analyzing the AU/AL response only to the southward IMF $B_{\mathrm{Z}}$ turning.

\section{Two events}

In this section we show two events selected to illustrate the typical response of the ionospheric current system to abrupt southward turnings of the IMF. As we will argue in the discussion the solar induced ionospheric electrical conductivity plays a central role and hence we show contrasting events where most of the oval is in darkness and where most of the oval is sunlit, respectively.

To illustrate the typical response of the ionospheric current system as measured by the ground based magnetometers we show in Fig. 1 an event for which nearly the entire auroral zone is in darkness. Superposed onto the polar plot are ground magnetic field vectors (units of $\mathrm{nT}$ ) rotated $90^{\circ}$ clockwise to indicate the equivalent current direction. The line plots show the three components of the propagated IMF and the AUd/ALd and AUs/ALs indices. The IMF $B_{\mathrm{Z}}$ southward turning took place at $\sim 06: 55$ UT following an extended period of northward $B_{\mathrm{Z}}$. After the southward turning the IMF $B_{\mathrm{z}}$ was fairly stable southward at approximately $-3 \mathrm{nT}$, which we show later is the average for our events. None of the four AU/AL indices showed any response to the changing IMF conditions. In contrast to the scalar auroral electrojet indices the three polar plots provide global information although the conclusion appears to be the same. Thus in this event where most of the auroral region was in darkness we find little (if any) response of the indices to the southward turning.

To investigate the dependence on the sunlight we show in Fig. 2 a typical event where nearly the entire auroral zone is sunlit. The IMF $B_{\mathrm{Z}}$ behavior is very similar to the previous example: an extended period of northward $B_{\mathrm{Z}}$ is followed by an extended period of southward $B_{\mathrm{Z}}$ of approximately $-3 \mathrm{nT}$, with a sharp transition at 05:22 UT. In agreement with the previous event the ALd, and AUd do not show any changes until the onset of a weak auroral event at 06:24 UT at which point our analysis is terminated. The ALs is nearly constant until the onset. A weak $(\sim 60 \mathrm{nT})$ intensification at dawn seen by the Image chain located on the dayside around 07:00 MLT does not exceed the ALs contributing stations located near dusk and thus this response does not define the ALs. One could speculate that this is due to terminator effects but a close investigation of the magnetograms for a few weeks surrounding the event does not support this. The AUs, however, starts a gradual intensification about $\sim 20 \mathrm{~min}$ after the southward turning. It gradually intensifies for roughly $40 \mathrm{~min}$ until it maximizes at $\sim 100 \mathrm{nT}$ after which it stays fairly constant despite the introduction of a small auroral nighttime event. A closer inspection of the superposed ground perturbation vectors show that the AUs intensification is seen at many stations located on the dayside. The vast number of measured ground perturbations indicates a one cell pattern that does not appear to change significantly from $05: 15$ UT to $05: 40$ UT despite the southward turning. At 06:20 UT the one cell has changed direction and there may be a hint of a dawn cell seen at the east coast of Greenland.

\section{Data base analysis}

We now investigate the AU/AL response statistically to the southward turning of the IMF, using all 73 events. The two events discussed above appear to indicate that the response of the auroral electrojets to abrupt southward turning is dependent on the solar source of ionospheric conductivity. It is most reasonable, then, to separate the analysis into an analysis of the AU/AL indices on the nightside and on the dayside (AUd/ALd and AUs/ALs, respectively).

Figure 3 shows the superposed epoch analysis for all 73 events with the time of the southward turning defined as $T=0$. The IMF $B_{\mathrm{z}}$ and $B_{\mathrm{y}}$ for all events (black lines) and median 


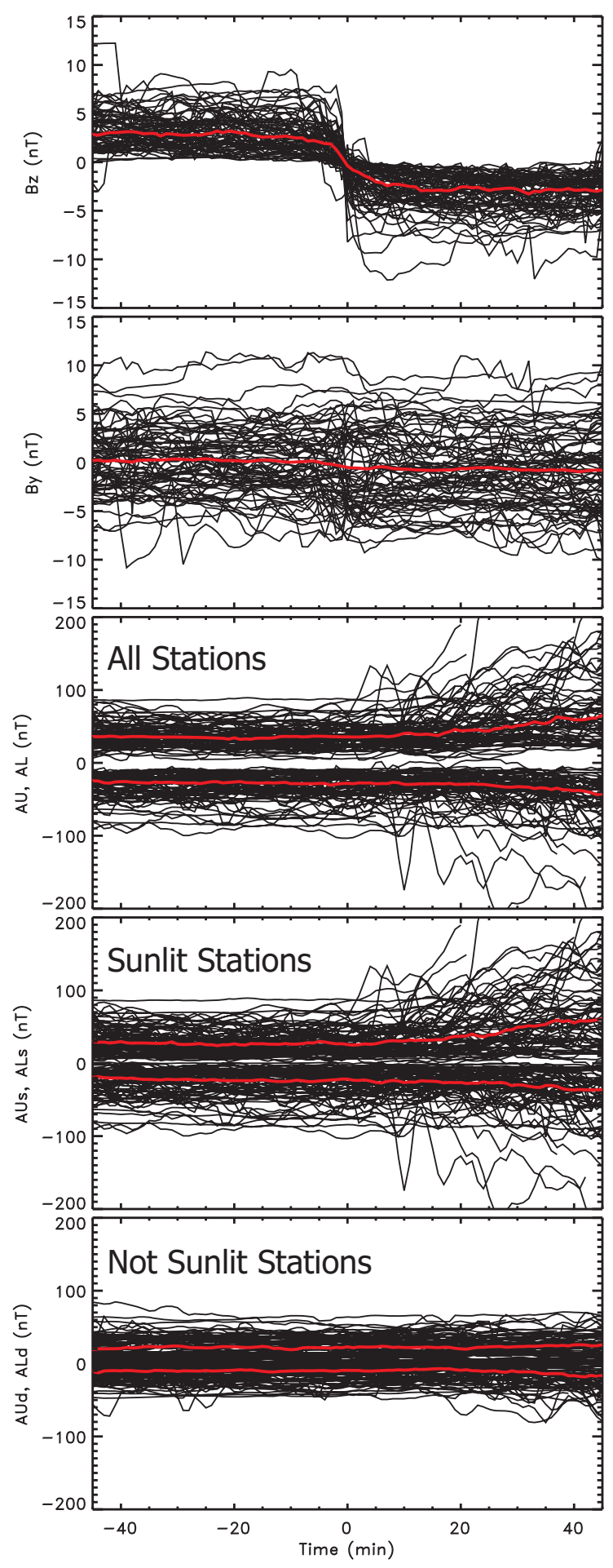

Fig. 3. Superposed epoch analysis for all 73 events (black lines) and median (red line) with the time of the southward turning defined as $T=0$. Top panel show the IMF $B_{\mathrm{z}}$; second panel show the IMF $B_{\mathrm{y}}$; third panel show AL/AU deduced from all stations; fourth and fifth panels show the AUs/ALs and AUd/ALd, respectively. (red line) are shown in the top panels. Before the transition the values of $B_{\mathrm{Z}}$ ranged from $0 \mathrm{nT}$ to $12 \mathrm{nT}$ with an average of $+2.9 \mathrm{nT}$ and after the transition the range was $-12 \mathrm{nT}$ to $0 \mathrm{nT}$ with an average of $-2.8 \mathrm{nT}$. Hence, for half the events the $B_{\mathrm{Z}}$ was less than $-2.8 \mathrm{nT}$ after the transition. The IMF $B_{\mathrm{y}}$ was between $+10 \mathrm{nT}$ and $-10 \mathrm{nT}$. The median is very close to zero although a weak negative slope may be detectable just before the transition. The third panel shows the traditional $\mathrm{AL} / \mathrm{AU}$ deduced from all stations. Both the $\mathrm{AL}$ and the $\mathrm{AU}$ start very gradual intensifications $\sim 24 \mathrm{~min}$ and $\sim 7 \mathrm{~min}$ after the $B_{\mathrm{Z}}$ transition respectively. AU increases from $\sim 35 \mathrm{nT}$ to $\sim 65 \mathrm{nT}$ while the $|\mathrm{AL}|$ shows a somewhat smaller intensification from $\sim 25 \mathrm{nT}$ to $\sim 40 \mathrm{nT}$. The second selection criterion $(|\mathrm{AL}|$ and $\mathrm{AU}<100 \mathrm{nT}$ for $45 \mathrm{~min}$ prior to southward turning) is the cause of the moderate values prior to the transition but we do not impose any requirement on the AU/AL after the transition.

The two bottom panels show the separation of the indices into sunlight and not sunlit components, AUs/ALs and AUd/ALd, respectively. For the sunlit stations the median AUs shows a gradual intensification in agreement with $\mathrm{AU}$ but starting perhaps a few minutes earlier. Its magnitude is larger than AU because the AUd stations add to the statistics for the median but not to the intensification. The ALs and the ALd medians on the other hand do not show any change until near the end of our analysis period. Thus we find a difference in the behavior of the AL/AU on the dayside and nightside with the former showing a clear response to the southward turning (but delayed) while the latter appears almost unaffected.

We can highlight these changes in the AU/AL by subtracting the values of the indices at the time of the onset, thereby emphasizing any systematic changes that may take place. Figure 4 shows the variations from the time of the southward turning for ALs/AUs and ALd/AUd. The median shown in red clearly shows an increase in the AUs while the median ALs only show a modest decrease of $\sim 5 \mathrm{nT}$ toward the end of the window. Naturally, there are individual traces showing larger excursions than the median. On the nightside the AUd is unaffected by the changing conditions of the IMF $B_{\mathrm{Z}}$ while ALd may indicate a minor decrease. We can further investigate these changes by plotting the normalized distributions of $\Delta \mathrm{AU}$ and $\Delta \mathrm{AL}$ for the dayside and nightside respectively (Fig. 5). We do that prior to the southward turning $(T=-10 \mathrm{~min})$ and after $(T=10,25,40 \mathrm{~min})$. For the $\Delta \mathrm{AUd}$ we find that on the nightside the distributions appear to widen slightly (and the RMS increases) as a function of time. The increase in the RMS, however, is not due to an intensification of the eastward electrojet since the distribution after $40 \mathrm{~min}$ is fairly symmetric around zero. In contrast, the $\Delta$ AUs distribution at $T=40 \mathrm{~min}$ on the dayside is highly asymmetric which we can explain as an intensification of the eastward electrojet. For the $\Delta \mathrm{ALs}$ and $\Delta \mathrm{ALd}$ the signatures are more subtle. Again, the RMS is increasing on the dayside and the distribution at $T=40 \mathrm{~min}$ is clearly skewed towards negative 

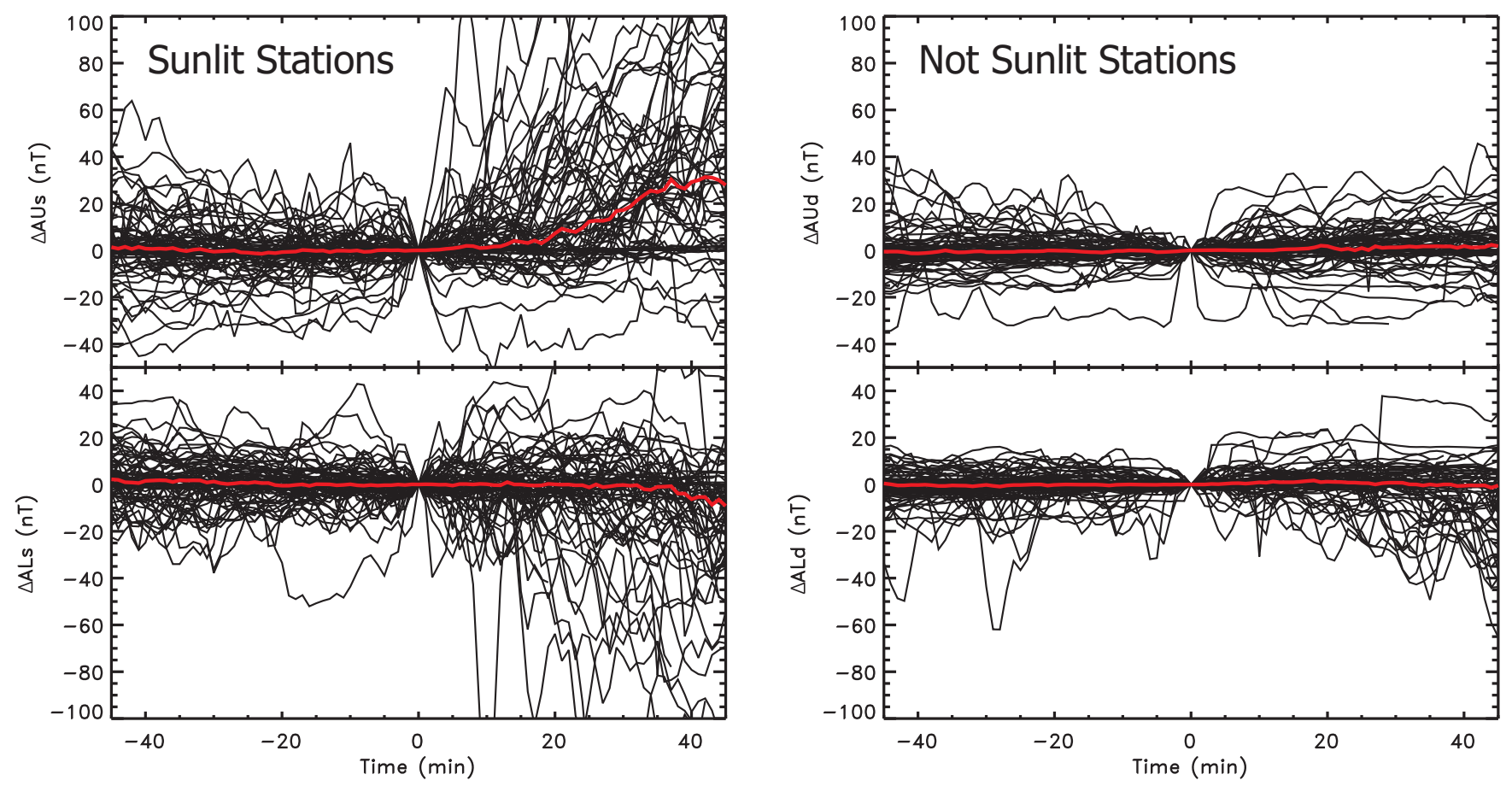

Fig. 4. Change of ALs/AUs and ALd/AUd from the time of the southward turning. The median is shown in red.

values which we can interpret as an intensification of the westward electrojet. For the nightside the $\Delta$ ALd indicates a minor negative tail but it also shows a significant increase in the probability of positive values which would indicate a weakening of the westward electrojet. In conclusion we find striking differences in the spread of the individual traces (and the normalized distributions) of the dayside and nightside indices indicating a clear difference in the dayside/nightside response of the electrojets.

The apparent peculiar results for the dayside eastward electrojet ( $\triangle \mathrm{AUs}$ ) may require additional comments. We argue that there are two distributions in the top left panel of Fig. 5: 1) events for which the two cell convection pattern is poleward of the conductance; 2) events for which the two cell convection pattern overlaps the solar induced conductance. For the first group the terminator is located far on the dayside and no response will be seen in ALs/AUs since the stations are located equatorward of the two cell convection pattern and these produce the near zero peak. For the second distribution the convection electric field and the solar induced conductance overlaps and the response is clear resulting in the pronounced positive tail. For the nightside the situation is simpler since there is no solar induced conductance and thus we expect a distribution centered around zero in agreement with the results.

\section{Discussion}

\subsection{Limitations to data set and methodology}

We address the response of the ionospheric current system to abrupt southward turnings of the IMF $B_{\mathrm{Z}}$ component. We utilize observations from more than 100 ground based magnetometers as enabled by the SuperMAG initiative. Although outstanding spatiotemporal coverage is provided by the SuperMAG collaborators, this dataset has its limitations. Before making any conclusions regarding the behavior of the global ionospheric current system we should keep these points in mind:

1. The basic limitation to the AL and AU indices is the fact that they are one-dimensional scalars, which simply indicates the maximum perturbation measured at one of the AE station locations. The only information they provide regarding the global distribution of the ionospheric currents is that the ground perturbations are weaker at the location of all other ground stations. Hence, they are not a measure of the global electrojet activity, although it is often found in the literature that the global electrojet configuration is presumptuously deduced. While our sub-indices (AUs/AUd and ALs/ALd) do not enable us to deduce the instantaneous global westward electrojet morphology they do more information that the classical AU/AL by providing a measure of the instantaneous maximum electrojet intensity in the sunlit as well as the not sunlit ionosphere. This is sufficient to determine the 


\section{Sunlit Stations}
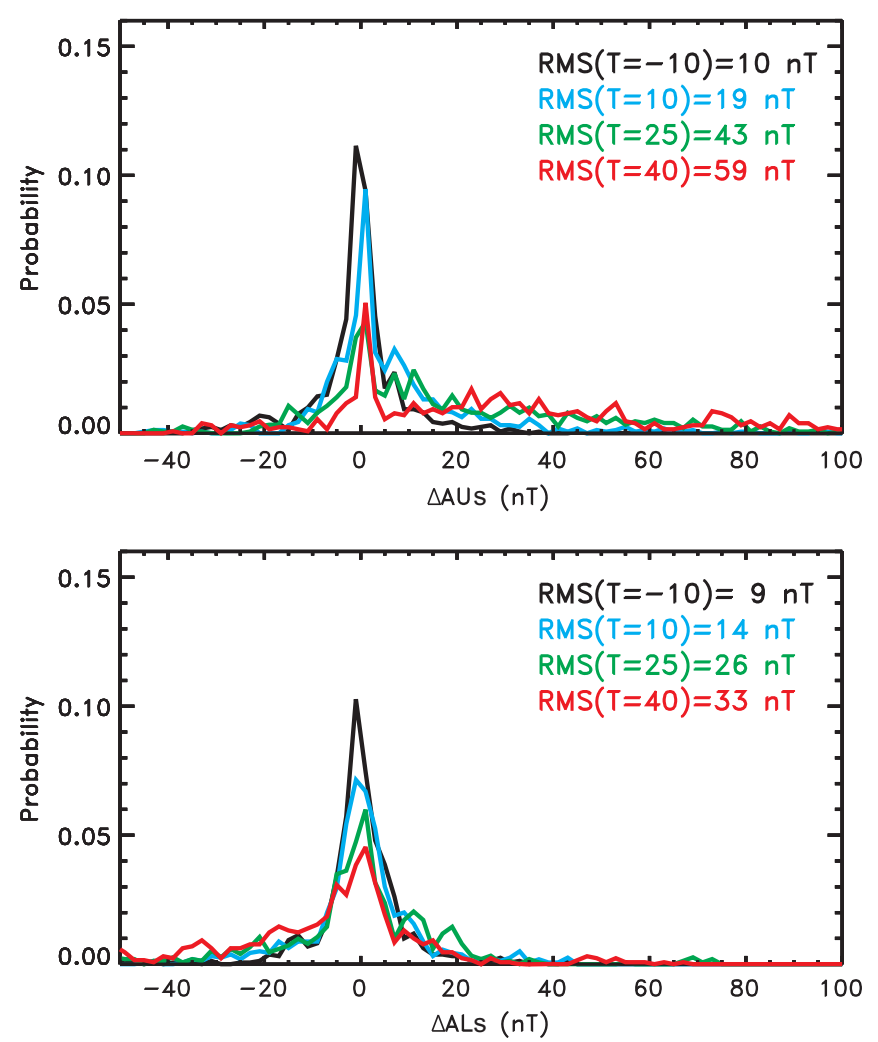

Not Sunlit Stations
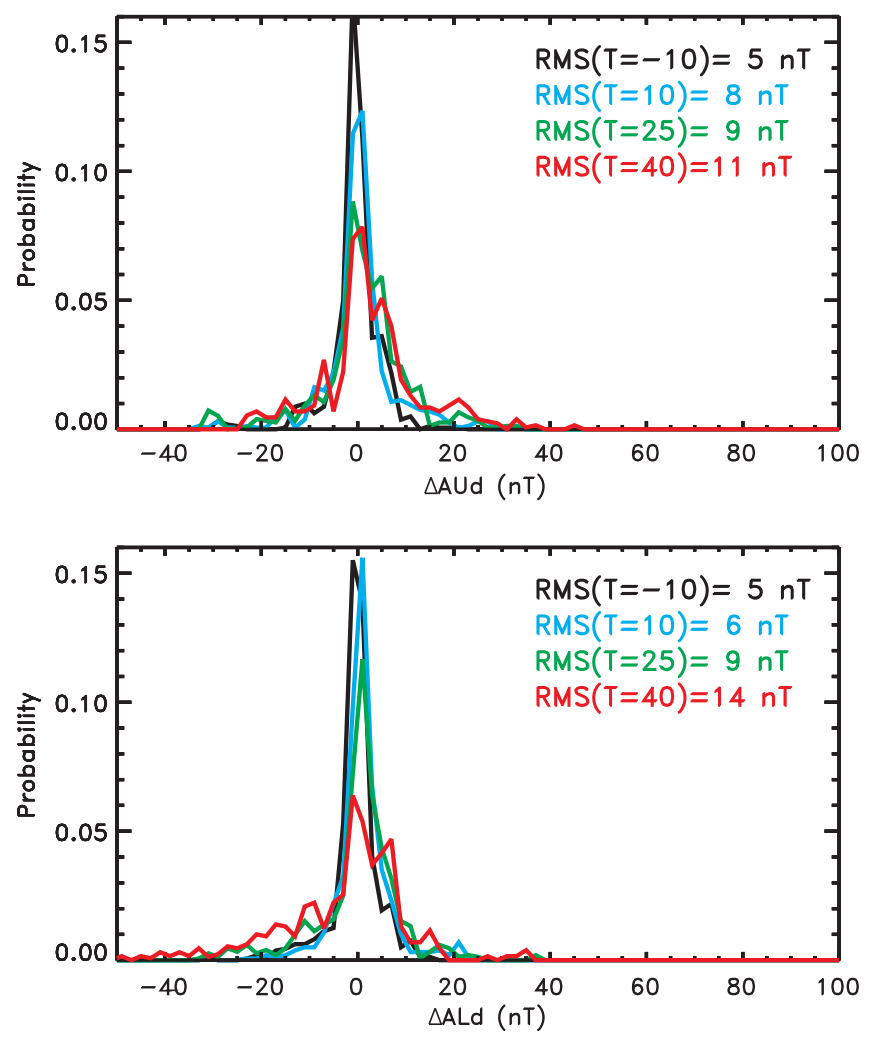

Fig. 5. Normalized distributions of $\Delta \mathrm{AUs}, \Delta \mathrm{AUd}, \Delta \mathrm{ALs}$ and $\Delta \mathrm{AUd}$ shown in Fig. 4 at four timestamps, $T=[-10,10,25,40]$. Root-meansquare is indicated as RMS.

dependence on solar induced conductivity and thereby address the objectives of the paper.

2. The indices are only calculated from the north-south components of the ground perturbations so any significant east-west response will not be detected. Thus a rotation of a perturbation vector can appear as a change in the magnitude of the AU/AL indices.

3. It is possible that significant currents are flowing in the ionosphere undetected by the ground based magnetometers. A current system consisting of field-aligned currents closed by Pedersen currents without any Hall currents does not produce any significant perturbations on the ground at auroral latitudes. This scenario requires a Hall to Pedersen conductance ratio $\ll 1$ as a result of soft particle precipitation with characteristic energies of precipitating electrons no more than a couple of hundreds of $\mathrm{eV}$. In comparison sunlight alone provides a ratio of $\sim 1.2$ depending on solar zenith angle and solar $10.7 \mathrm{~cm}$ flux (Moen and Brekke, 1993).

4. Since the solar induced conductance plays a key role the ALs/AUs are expected to have a pronounced seasonal dependence.
5. For most events the changes in the indices are small, raising the question of the sensitivity of our measurements. The sensitivity can be investigated by plotting the normalized distributions of $\triangle \mathrm{AU}$ and $\triangle \mathrm{AL}$ for the dayside and nightside prior to the southward turning (black lines in Fig. 5). We find the root-mean-square (RMS) of the distributions to be $5 \mathrm{nT}$ and $9 \mathrm{nT}$ for the nightside and dayside respectively. Hence, trends in our measured median values can elucidate rather subtle responses of the ionospheric current system to external and internal drivers.

\subsection{Relation to solar wind driver}

We now investigate whether the response of the indices to the southward turning is dependent on the strength of the solar wind driver as measured by the magnitude of the IMF $B_{\mathrm{Z}}$. That is, for negligible solar wind input the response would be likewise negligible. We stated earlier that the median IMF $B_{\mathrm{Z}}$ for all events after the southward turning is $-2.8 \mathrm{nT}$. We calculated the median of the IMF $B_{\mathrm{Z}}$ (from southward turning to end of analysis) and show this in the top panel of Fig. 6. We find that the majority of the events had median values 

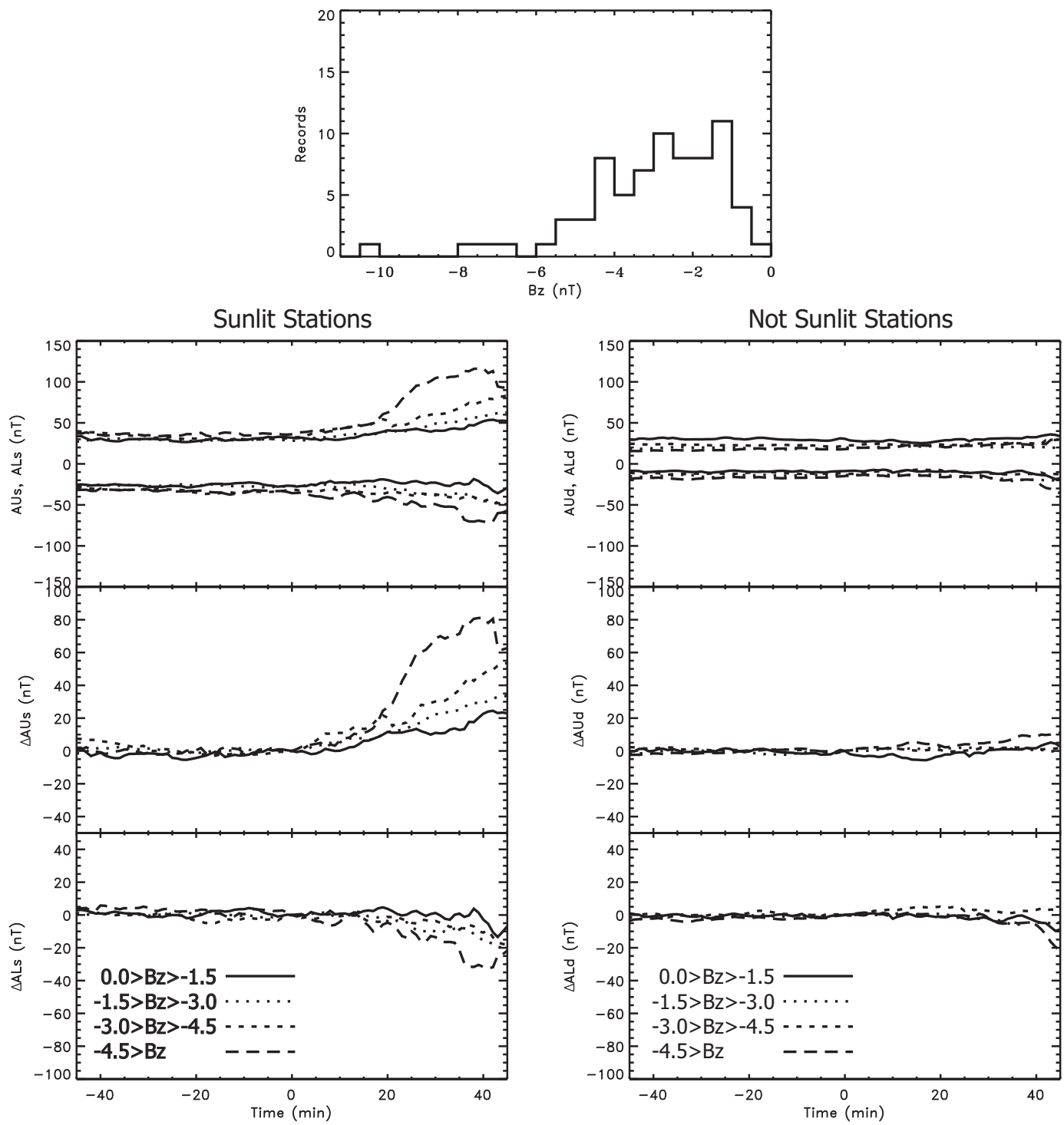

Fig. 6. Distribution of the median IMF $B_{\mathrm{Z}}$ during the pre-unloading phase after the southward turning (top panel). Left column shows AUs/ALs for four intervals of $B_{\mathrm{Z}}$ (top panel) and change in AUs/ALs from time of southward turning (bottom two panels). Right column has same format as left column but for nightside stations.

in the range -1.0 to $-4.5 \mathrm{nT}$. To investigate the effects of $B_{\mathrm{Z}}$ magnitude on the response we divided all events into four groups: $0>B_{\mathrm{Z}}>-1.5 \mathrm{nT}$ (16 events); $-1.5>B_{\mathrm{Z}}>-3.0 \mathrm{nT}$ (26 events); $-3.0>B_{\mathrm{Z}}>-4.5 \mathrm{nT}$ ( 20 events); $-4.5>B_{\mathrm{Z}} \mathrm{nT}$ (11 events) and performed a similar analysis of the AU/AL indices as above for each of these groups. The averages (calculated for the same time period as the IMF $B_{\mathrm{Z}}$ above) of each of the AUs/ALs and AUd/ALd subgroups appear in the top panels and the averages of the changes since the southward turning in the bottom panels. Both the AUs and ALs subgroups show a clear IMF $B_{\mathrm{Z}}$ dependence although the ALs is weaker by a factor of approximately three. For stations in darkness we find no systematic dependence on the IMF $B_{\mathrm{Z}}$ intensity. Thus the response of the dayside current system shows a clear dependence on the magnitude of the IMF $B_{\mathrm{Z}}$ while the nightside shows no dependence. While the fewer events in each subgroup compared to the entire group will degrade the sensitivity of the calculations of the median values we consider changes beyond $10 \mathrm{nT}$ to be significant.

Like the IMF $B_{\mathrm{Z}}$ dependence it seems reasonable to assume that the ionospheric current system response is also a function of the solar wind energy input. As a rough estimate of the energy input to the magnetosphere we utilized the Akasofu epsilon parameter (Perreault and Akasofu, 1978; in SI units $\varepsilon=10^{7} \cdot V B^{2} \sin ^{4}(\theta / 2) l_{0}^{2}$, where $l_{0}$ is $7 R_{\mathrm{E}}, B$ is the magnitude of the IMF, and $\theta$ is the IMF clock angle). We realize that more complex coupling functions have been published (e.g. Newell et al., 2007) but for a qualitative test 

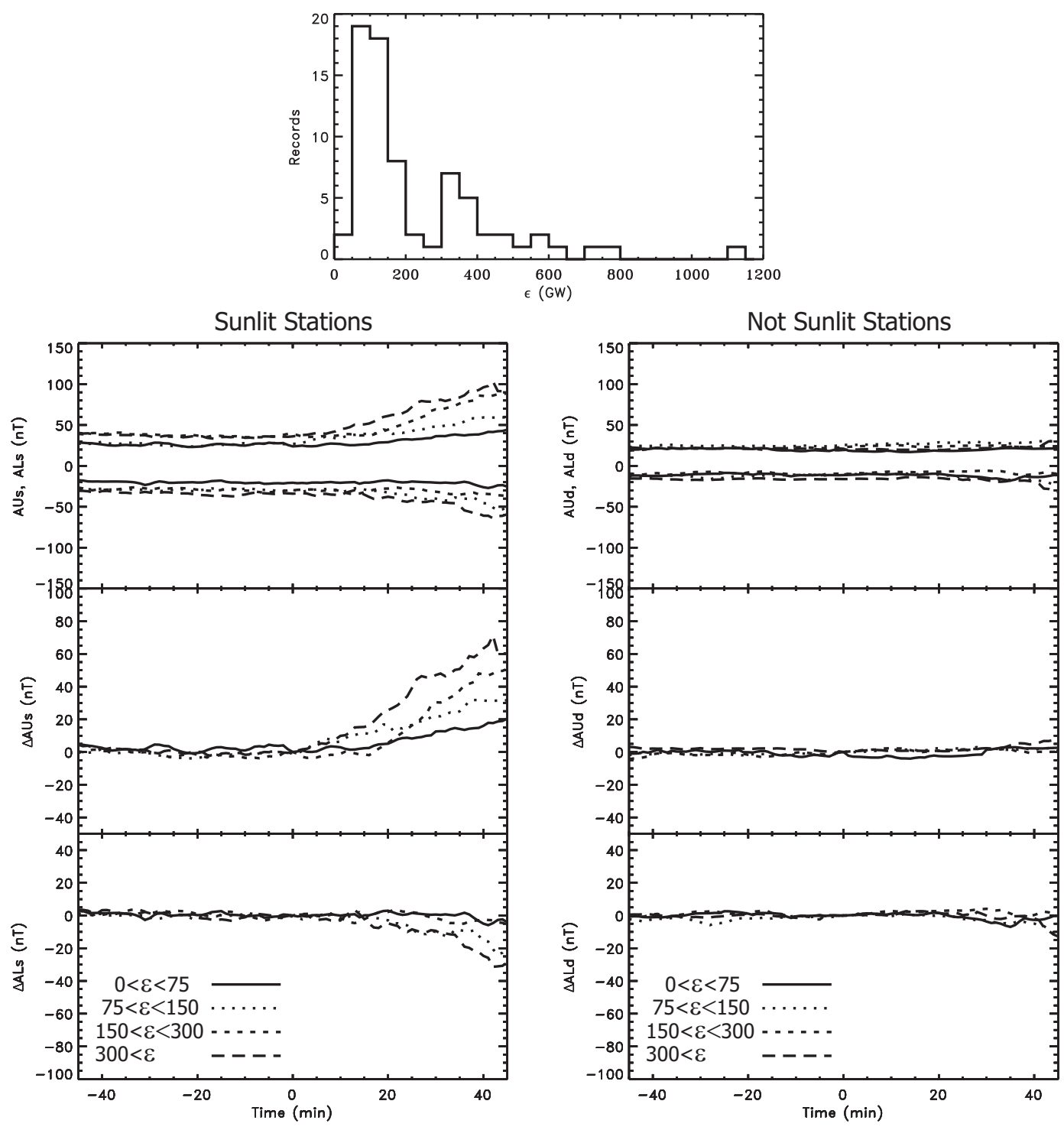

Fig. 7. Same format as Fig. 6 but for $\varepsilon$.

of the above hypothesis the $\varepsilon$ parameter is sufficient. As for the above IMF $B_{\mathrm{Z}}$ analysis we calculated the median of the $\varepsilon$ (from southward turning to end of analysis) and divided the events into four groups: $0<\varepsilon<75 \mathrm{GW}$ (11 events); $75<\varepsilon<150 \mathrm{GW}$ ( 28 events); $150<\varepsilon<300 \mathrm{GW}$ (11 events); and $300<\varepsilon \mathrm{GW}$ ( 23 events). Following Akasofu (1981), input power exceeding $10^{11} \mathrm{~W}(100 \mathrm{GW})$ can be considered a substorm level, i.e., if this input exists for some time, a substorm is likely to occur. As seen in the top panel most of our events $(\sim 71 \%)$ exceeded this $100 \mathrm{GW}$ threshold. In qualitative agreement with the IMF $B_{\mathrm{Z}}$ results the dayside stations show increasing perturbations for increasing energy input (Fig. 7). Again, the $|\mathrm{ALs}|$ appears to be considerably weaker than the AUs. For stations located in darkness the overhead electrojets do not show any significant dependence on the energy input.
As we find above the magnitude of AUs/ALs shows clear dependence on time as well as IMF $B_{\mathrm{Z}}$ and $\varepsilon$. We can highlight the magnitude dependence by plotting the change in AU/AL 35 min after the southward turning as a function of the median $B_{\mathrm{Z}}$ and median $\varepsilon$ (Fig. 8). From the previous analysis we know that the changes in $\mathrm{AU}$ and $\mathrm{AL}$ are purely due to the response of the dayside; hence we have AL=ALs and $\mathrm{AU}=\mathrm{AU}$. The scatter in all four plots indicates that likely other parameters play a role in this relationship (for example seasonal dependence). However, a trend seems to be apparent in all panels with the $\Delta$ AUs dependence on IMF $B_{\mathrm{Z}}$ being the most convincing. For the epsilon parameter the $\mathrm{AL}$ and AU show similar asymmetric responses although the difference in slope is only a factor of $\sim 2$. Assuming a solar wind velocity of $400 \mathrm{~km} / \mathrm{s}$ and a pre-unloading phase duration of $35 \mathrm{~min}$ we can convert these empirical relationships 

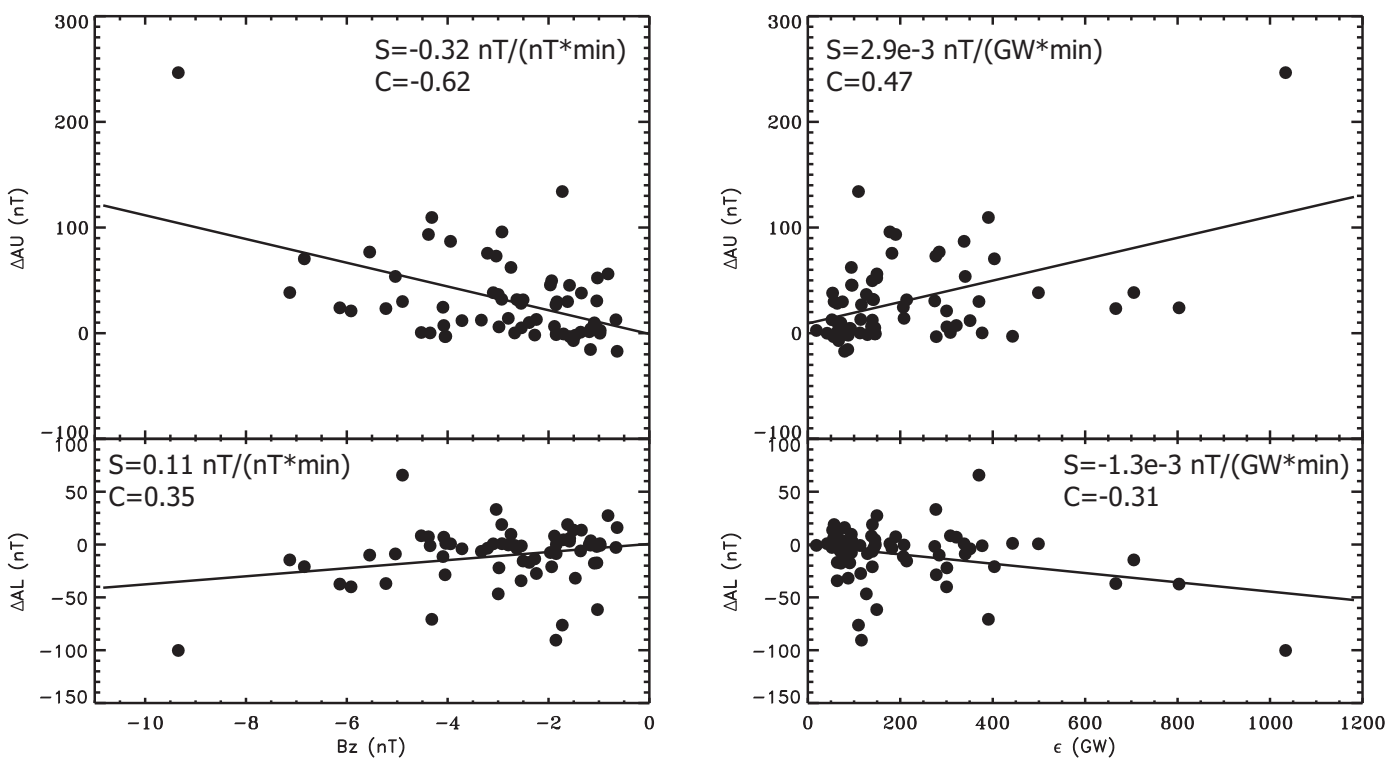

Fig. 8. Change in AU/AL at $T=35$ min relative to $T=0$ min plotted as a function of median $B_{\mathrm{Z}}$ and median $\varepsilon$. The median is calculated for the time interval $T=0$ to $T=35 \mathrm{~min}$.

to $\mathrm{AUs}=28 \mathrm{nT} /(\mathrm{mV} / \mathrm{m})$ and $\mathrm{ALs}=10 \mathrm{nT} /(\mathrm{mV} / \mathrm{m})$ where the solar wind electric field is given by the $\mathrm{x}$-component of the velocity and the southward IMF component: VBs. These numbers are in good agreement with the results published by McPherron et al. (1988) who suggested that the growth phase currents are very closely proportional to the rectified solar wind electric field and listed scaling parameters to be 17 and $37 \mathrm{nT} /(\mathrm{mV} / \mathrm{m})$ for two different substorms, although they pointed out that these parameters are expected to vary from event to event. Our relationships are deduced for the dayside indices (AUs/ALs) during the pre-unloading phase while McPherron et al. determined the scaling parameters for the growth phase of two strong substorms without any knowledge of which station was determining the index. With these differences in mind we find the apparent agreement remarkable.

\subsection{Seasonal dependence}

The scatter in Fig. 8 may be partly due to seasonal effects. Gjerloev et al. (2007) found the average position of the growth phase oval at the noon meridian to be at $\sim 77^{\circ}$ magnetic latitude. To remove the seasonal dependence of the $\triangle$ AUs in Fig. 8 we calculated the solar zenith angle for each event at the point $\mathrm{P}=\mathrm{P}\left(\mathrm{MLT}=12, \mathrm{MLAT}=77^{\circ}\right)$ and fitted the $\triangle \mathrm{AUs}$ with the simple function: $\triangle \mathrm{AUs}(\chi)=$ $-19.6 \tanh ((\chi-87.3) / 7.7)-6$, where $\chi$ is the solar zenith angle in degrees at $\mathrm{P}$. Removing this dependence from $\Delta \mathrm{AUs}=\Delta \mathrm{AUs}\left(B_{\mathrm{Z}}\right)$ increases the correlation coefficient from 0.62 to 0.72 .

Since we have shown that the response of the AU/AL indices to the solar wind driver has season dependence we must

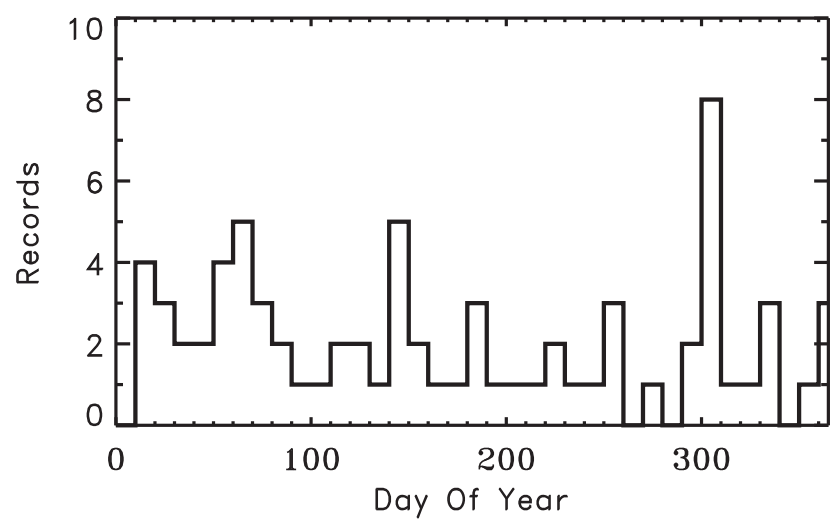

Fig. 9. Event distribution as a function of day of year. Records indicate number of events per 10 day increments.

then ask if our event selection criteria inadvertently have biased our events toward a particular season. A plot of the number of events as a function of day of the year in Fig. 9 , however, shows no seasonal dependence. The other interesting consequence of the seasonal dependence is that the current systems in the two hemispheres must be non-conjugate.

\subsection{Relation to subsequent substorms}

One could speculate that the intensity of a substorm (peak $\mathrm{AL}$ ) is related to the intensity of the growth phase (AL prior to substorm expansion phase onset). That is a strong substorm requires a period of strong loading, which presumably results in a significant AU/AL prior to the substorm expansion phase onset (e.g. Weimer, 1994). Following this 

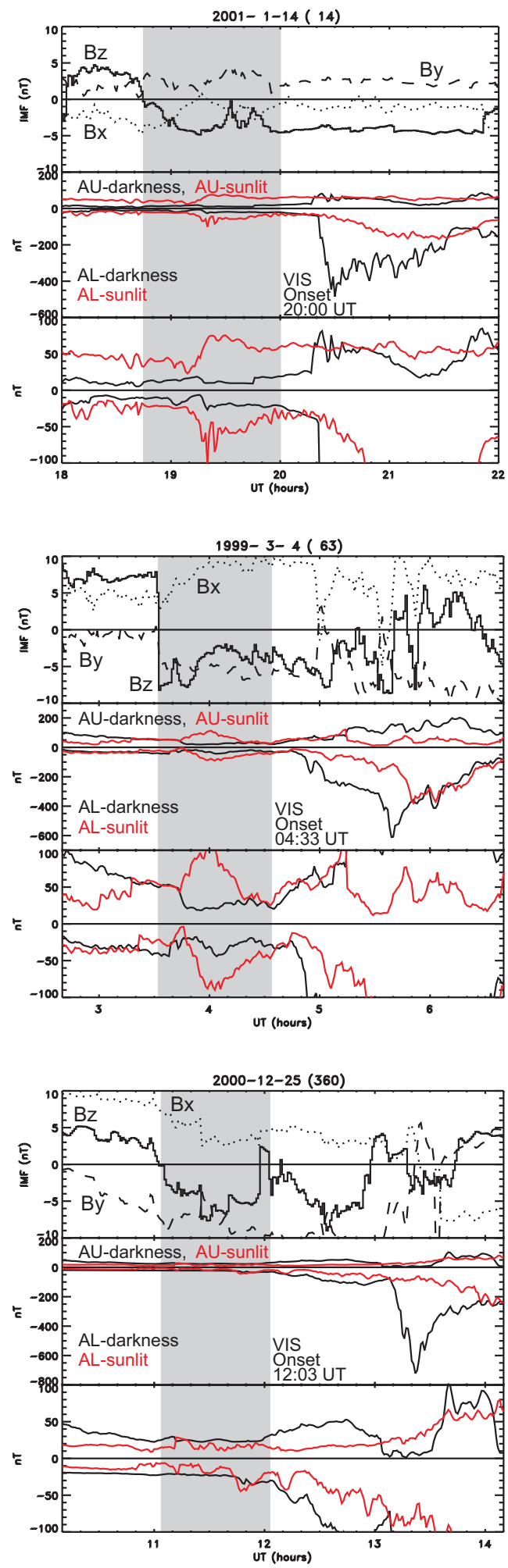

Fig. 10. Three examples of events that develop into strong substorms. Top panel shows the IMF, the second and third panels both show the AU/AL but in the third panel the y-axis is expanded to focus on any subtle pre-onset signature. The grey bar indicates the period between the southward turning and the onset of any abrupt auroral event. logic we can argue that the reason we find little response of the nightside ALd/AUd is simply that our selection criteria inadvertently selected events that developed into very weak substorms, so the AU/AL signature during the preunloading phase is not easily detectable. At first glance at the two examples in Figs. 1 and 2 this argument seems to be supported since both developed into very weak events, 130 and $140 \mathrm{nT}$ respectively. However, the distribution of the epsilon parameter in Fig. 7 would indicate a good range of substorm sizes. To verify a lack of a relationship we investigated events that developed into strong substorms, with peak values of $|\mathrm{AL}| \sim 480 / 620 / 730 \mathrm{nT}$, respectively (Fig. 10). For each event the top panel shows the IMF, the second and third panels both show the four AU/AL indices, but in the third panel the vertical axis is enlarged to focus on any subtle signatures preceding the substorm expansion phase onset. The grey bar indicates the period between the southward turning and the onset of any abrupt auroral event as identified in the Polar VIS images. All three events exceeded our 45 min analysis period with pre-unloading phase durations of roughly one hour. In the first two events both the AUs and the ALs intensify following the southward turning (but slightly delayed), while the last event does not show this response. We can, however, easily explain this lack of response by the location of the terminator, which was located at $\sim 75^{\circ} / 75^{\circ} / 65^{\circ} \mathrm{mag}$ netic latitude at noon, respectively. Thus there were no sunlit stations at auroral latitudes on the dayside for the third event.

In the first two events the electrojets in the dark ionosphere (as measured by AUd/ALd) show little response to the southward turning in agreement with our statistical results. The last event, however, is of particular interest since AL appears to display the classical gradual intensification prior to the apparent AL substorm expansion phase onset at 13:08 UT. This gradual intensification of the AL from 12:03 UT to 13:08 UT can, however, be attributed to a small substorm as identified from Polar VIS images (Fig. 11). Without images it would be very difficult to identify the existence of this event and the decrease in the AL trace could be mistakenly attributed to being solely directly driven rather than to the addition of an unloading event, as is the case.

\subsection{Lack of nightside response of AU/AL}

Our finding that the lack of response of the nightside AU/AL to the southward turning is in contrast to the classical view that the AL gradually decreases during the growth phase, beginning with the southward turning. We suggest four possible reasons:

1. Dayside currents. During the pre-unloading phase, that is before any nightside auroral activity, the AU/AL indices come from dayside stations. Without a careful identification of the locations of the AL/AU contributing stations one cannot assume that these indices are defined by stations that are measuring the nighttime auroral electrojet. 


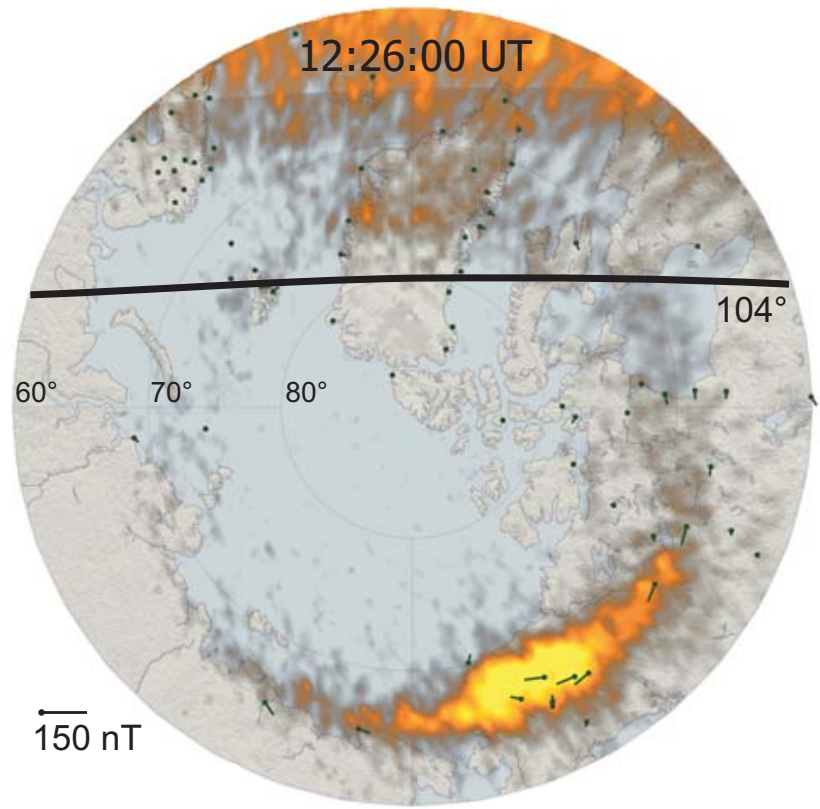

Fig. 11. Auroral activity at 12:26:00 UT on 25 December 2000 . Ground magnetic field vectors (units of nT) rotated $90^{\circ}$ clockwise to indicate the equivalent current direction superposed onto an image obtained at 12:26:17 UT by the Polar Visible Imaging System's Earth camera (courtesy L. A. Frank and J. B. Sigwarth). The camera provided global auroral images in the far ultraviolet (FUV) range of $\sim 124-149 \mathrm{~nm}$. Notice that the ionospheric currents are clearly associated with the auroral emissions thereby indicating that these currents are due to processes internal to the magnetosphere.

2. Growth phase terminology. During the pre-unloading phase we find no measureable response of the nightside ionospheric current system as measured by AU/AL. We have defined this period as starting at the southward turning of the IMF $B_{\mathrm{Z}}$ and ending at any abrupt unloading event (as seen by the Polar VIS Camera). Without these unloading events we find little response of the electrojets in the dark ionosphere and hypothesize that the ionospheric conductivity on the nightside is too low to drive any measureable currents and hence the response of AUd/ALd to the enhanced convection is insignificant. One can speculate that the diffuse aurora is intensified and hence ionospheric Hall conductance as a result of the southward turning of the IMF which combined with the enhanced convection would lead to an intensification of the electrojets. Our observations do not appear to support this scenario.

In contrast to our pre-unloading phase it is possible to drive significant ionospheric currents in the nightside ionosphere during the classical growth phase. It is well known that substorms are often preceded by pseudo- and/or multiple-onsets (as realized by Rostoker et al., 1980, which presented a consensus of a substorm definition working group). Associated with these precursor events is particle precipitation that enhances the ionospheric conductivity required to produce any measureable $\mathrm{AUd} / \mathrm{ALd}$, and thus contaminates the directly driven system (as seen in Fig. 11).

3. Selection methodology. The AL trace has been used to select, identify and organize substorms. For example the times of the substorm expansion phase onset may be determined by identifying the time at which the $\mathrm{AL}$ shows a sudden decrease. While this is convenient for large statistical studies the selected events will often be preceded by pseudo onsets and weak substorm expansion (Rostoker et al., 1980) and consequently the average AL will show a gradual intensification prior to the actual substorm expansion phase onset.

4. Prior events. Finally, the required ionospheric conductivity on the nightside can be provided by a preceding auroral event. That is, if a southward turning takes place during the recovery of a prior disturbance the particle precipitation may still be sufficient to produce significant ionospheric conductivity in the nighttime sector. This combined with an increase in the convection electric field caused by the southward IMF would result in a response of the AUd/ALd. This conclusion is in agreement with the study by Rostoker et al. (1983) which concluded that "the response of the magnetosphere-ionosphere current systems to changes in interplanetary conditions is dependent on the prior state of the system".

In our analysis we find negligible response of the nightside current system to $B_{\mathrm{Z}}$ southward turnings. Following the southward turning the global convection pattern is enhanced but this does not necessarily lead to significant intensifications of the ionospheric electrojets. In the literature the DP2 current system is often found to be synonymous with the global two-cell convection pattern but according to Ohm's law this requires the ionospheric conductivity distribution to be uniform. Unfortunately, this is most often ignored in the literature and the electrojets are depicted as flowing from the dayside to the nightside without any consideration to the conductivity gradients present at the terminators. Our results show that the classical global DP-2 global current pattern (e.g. Clauer and Kamide, 1985) is not a necessary consequence of a southward turning of the IMF.

\subsection{Terminator effect}

For the sunlit stations the $\mathrm{AU}$ and to a lesser extent the $\mathrm{AL}$ show a clear response to the southward transition but for the stations in darkness the response is very weak at best. This indicates a decoupling of the dayside and nightside ionosphere thereby indicating that auroral electrojet current continuity is not maintained across the terminators. The global 
Dayside Behavior of AU/AL

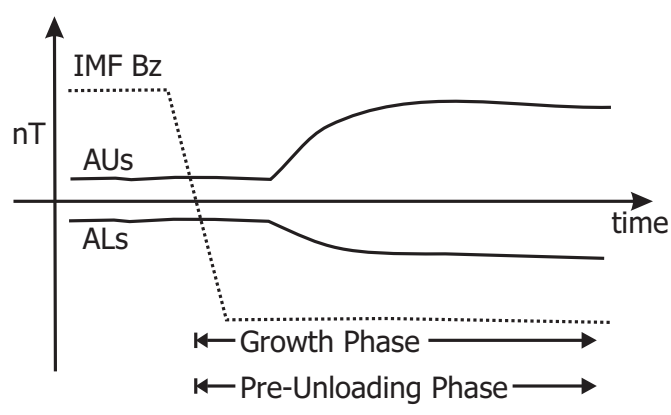

Nightside Behavior of AU/AL Two Cases

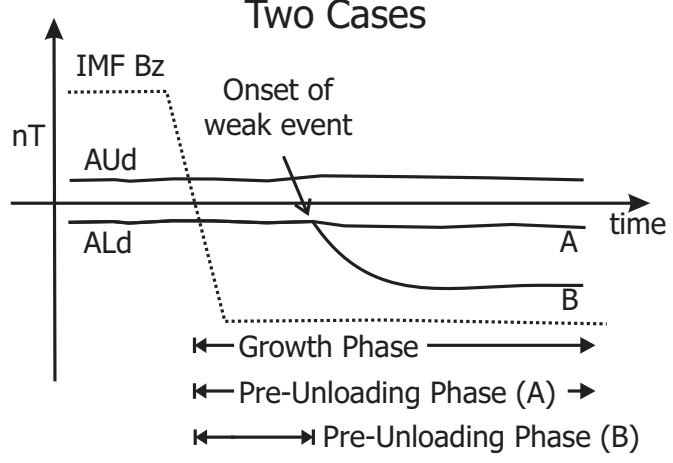

Fig. 12. Schematic summary figure showing the behavior of ALd for two different cases. Case A: An isolated substorm; and Case B: A weak event (e.g., a pseudo onset) preceding the substorm onset. For Case A both the growth phase and the "pre-unloading phase" end at the substorm onset. For Case B the "pre-unloading phase" ends at the onset of the weak event while the growth phase ends at the substorm onset.

convection electric field responds to a southward turning (e.g. Heppner and Maynard, 1987; Ruhoniemi et al., 1998) but we are not aware of any statistical study having shown the ionospheric conductivity distribution to likewise respond to a southward turning. Only if significant particle precipitation is present in the auroral zone around the terminator will the conductivity gradient be minor and current be maintained across the terminator. This, however, requires the southward turning to take place during the recovery phase of a prior substorm. Such a contamination has been effectively removed in the present study. Since the remaining ionospheric conductivity is primarily due to solar illumination, conductivity gradients are present only at the terminators. These will result in gradients of the electrojet currents across the terminator. An investigation of the ionospheric current pattern near the terminators and the possible coupling to the magnetosphere through field aligned currents is, however, not within the scope of the current paper. There is support for this argument in the literature. Rostoker et al. $(2006,1979)$ addressed the continuity of the eastward electrojet current in the dusk sector using 10 ground magnetometer stations in the Alberta meridian line and Isis 2 particle precipitation measurements. They suggested that upward field-aligned current flow occurs at the conductivity discontinuity between the sunlit and dark ionospheres.

\subsection{Schematic ALd behavior}

Figure 12 is a schematic summary figure of our findings. The figure shows the dayside and nightside behavior of the indices.

On the dayside we find a clear response of the electrojets to the southward turning of the IMF $B_{\mathrm{Z}}$. Both indices intensify with some delay although the intensification of the AUs is found to be about twice that of AL. Both the growth phase and the pre-unloading phase start at the southward turning and continue until the onset of a substorm expansion.
On the nighside the situation is slightly more complicated. We show two cases: In case A no significant auroral activity is present; and in case B a weak auroral event, for example, a pseudo onset or a weak substorm takes place as indicated on the figure. In case A neither AUd nor ALd show any noticeable response to the southward turning. The pre-unloading phase and the growth phase will both extend from the southward turning of the IMF $B_{\mathrm{Z}}$ until the onset of a substorm. In case B a weak auroral event takes place as indicated on the figure and due to the ionospheric current associated with this event initializes a downward trend in nightside auroral oval magnetic field perturbations that can be sufficiently strong to define the ALd. Hence, the ALd now provides information of the behavior of this current system. The pre-unloading phase and thus our analysis ends at the onset of the weak event while the classical growth phase extends from the southward turning of the IMF $B_{\mathrm{Z}}$ until the onset of a substorm expansion.

\section{$7 \quad$ Summary and conclusions}

We have performed a study of the behavior of the auroral electrojet indices following abrupt southward turnings of the IMF $B_{\mathrm{Z}}$. The auroral electrojet indices were calculated from observations made by more than 100 ground based stations provided by the SuperMAG collaborators. Based on three simple criteria we selected 73 events. In each event the interval of analysis started at the time of the IMF $B_{\mathrm{Z}}$ southward turning and ended $45 \mathrm{~min}$ later or at the onset of any abrupt unloading event, regardless of size. We refer to this period as the "pre-unloading phase". To isolate the dependence of the auroral electrojets on the ionospheric solar induced conductivity during this phase we calculated AU/AL separately for sunlit stations (AUs/ALs) and stations in darkness (AUd/ALd). Based on events and statistical analysis we can conclude that following a southward turning of the IMF 
$B_{\mathrm{Z}}$ the AUd/ALd indices show no response while the dayside indices, AUs/ALs, clearly intensify. The intensification of AUs/ALs is dependent on the intensity of the solar wind driver (as measured by IMF $B_{\mathrm{Z}}$ or the Akasofu $\varepsilon$ parameter). The lack of AUd/ALd response does not depend on the intensity of any subsequent substorm.

We found that during these isolated events the ionospheric current system is primarily confined to the sunlit ionosphere. This truncated version of the classical global DP-2 current system has little westward and eastward electrojet current flowing from the dayside across the terminator into the nightside. Because of its conductivity dependence on the solar zenith angle, this current system pattern would be expected to be highly dependent on UT and DOY, and thus be asymmetric between hemispheres. The classical global DP-2 current system requires the introduction of additional conductivity, especially in the nightside auroral oval, from energy sources internal to the magnetosphere sufficient to overwhelm the conductivity gradients around the terminator. Thus we argue that the response of the ionospheric current system to a southward turning of the IMF depends on the state of the magnetosphere-ionosphere system and that the classical twocell global DP-2 current system is not a necessary consequence.

Finally, we speculate that the difference in behavior of the dayside and nightside auroral indices indicates a decoupling of the ionospheric current from the dayside to the nightside ionosphere and suggests that auroral electrojet continuity is not maintained across the terminators.

Acknowledgements. This work was made possible by the NASA NNX08AM32G grant. We would like to acknowledge L. A. Frank and J. B. Sigwarth for the Polar VIS Earth Camera Image. We also acknowledge A. T. Y. Lui for his comments to the manuscript. One of us (RAH) acknowledges support through sub-award 962353 with JHU/APL. For the ground magnetometer data we gratefully acknowledge: Intermagnet; USGS, Jeffrey J. Love; Danish Meteorological Institute; CARISMA, PI Ian Mann; CANMOS; The S-RAMP Database, PI K. Yumoto and K. Shiokawa; The SPIDR database; AARI, PI Oleg Troshichev; The MACCS program, PI M. Engebretson, Geomagnetism Unit of the Geological Survey of Canada; GIMA, PI John Olson; MEASURE, UCLA IGPP and Florida Institute of Technology; SAMBA, PI Eftyhia Zesta; 210 Chain, PI K. Yumoto; SAMNET, PI Farideh Honary; The institutes who maintain the IMAGE magnetometer array, PI Ari Viljanen; PENGUIN; AUTUMN, PI Martin Conners; South Pole and McMurdo Magnetometer, PI's Louis J. Lanzarotti and Alan T. Weatherwax; SuperMAG, PI Jesper W. Gjerloev.

Topical Editor R. Nakamura thanks G. Rostoker and another anonymous referee for their help in evaluating this paper.

\section{References}

Ahn, B.-H., Kamide, Y., and Akasofu, S.-I.: Global ionospheric current distributions during substorms, J. Geophys. Res., 89, 1613-1625, 1984.
Ahn, B.-H., Moon, G.-H., Sun, W., Akasofu, S.-I., Chen, G. X., and Park, Y. D.: Universal time variation of the Dst index and the relationship between the cumulative AL and Dst indices during geomagnetic storms, J. Geophys. Res., 107, A11, doi:10.1029/2002JA009257, 2002.

Akasofu, S.-I.: Energy coupling between the solar wind and the magnetosphere, Space Sci. Rev., 28, 121-190, 1981.

Allen, J. H. and Kroehl, H. W.: Spatial and temporal distributions of magnetic effects of auroral electrojets as derived from AE indices, J. Geophys. Res., 80, 3667-3677, 1975.

Baumjohann, W.: Ionospheric and field-aligned current systems in the auroral zone: A concise review, Adv. Space. Res., 2, 55-62, 1983.

Clauer, C. R. and Kamide, Y.: DP 1 and DP 2 current systems for the March 22, 1979, substorms, J. Geophys. Res., 90, 1343-1354, 1985.

Frank, L. A., Sigwarth, J. B., Craven, J. D., Cravens, J. P., Dolans, J. S., Dvorsky, M. R., Hardebeck, P. K., Harvey, J. D., and Muller, D. W.: The visible imaging-system (VIS) for the Polar spacecraft, Space. Sci. Rev., 71, 297-328, 1995.

Gjerloev, J. W., Hoffman, R. A., Tanskanen, E., Friel, M., Frank, L. A., and Sigwarth, J. B.: Auroral electrojet configuration during substorm growth phase, Geophys. Res. Lett., 30(18), 1927, doi:10.1029/2003GL017851, 2003.

Gjerloev, J. W., Hoffman, R. A., Sigwarth, J. B., and Frank, L. A.: Statistical description of the bulge-type auroral substorm in the far ultraviolet, J. Geophys. Res., 112, A07213, doi:10.1029/2006JA012189, 2007.

Gjerloev, J. W., Hoffman, R. A., Sigwarth, J. B., Frank, L. A., and Baker, J.: The typical auroral substorm: A bifurcated oval, J. Geophys. Res., 113, A03211, doi:10.1029/2007JA012431.

Gjerloev, J. W.: A Global Ground-Based Magnetometer Initiative, EOS, 90, 27, 230-231, 2009.

Heppner, J. P. and Maynard, N. C.: Empirical high-latitude electric field models, J. Geophys. Res., 92, 4467-4489, 1987.

Iijima, T. and Nagata, T.: Signatures for substorm development of the growth phase and expansion phase, Planet. Space. Sci., 20, 1095-1112, 1972.

Iyemori, T.: Time delay of the substorm onset from the IMF southward turning, J. Geomagn. Geoelectr., 32, 267-273, 1980.

Kamide, Y. and Vickrey, J. F.: Variability of the Harang discontinuity as observed by the Chatanika radar and the IMS Alaska magnetic chain, Geophys. Res. Lett., 10, 159-162, 1983.

Kamide, Y. and Kokubun, S.: Two-component auroral electrojet: Importance for substorm studies, J. Geophys. Res., 101, 1302713046, 1996.

Lu, G., Holzer, T. E., Lummerzheim, D., Ruohoniemi, J. M., Stauning, P., Troshichev, O., Newell, P. T., Brittnacher, M., and Parks, G.: Ionospheric response to the interplanetary magnetic field southward turning: Fast onset and slow reconfiguration, J. Geophys. Res., 107, 1153, doi:10.1029/2001JA000324, 2002.

McPherron, R. L.: Growth phase of magnetospheric substorms, J. Geophys. Res., 75, 5592-5599, 1970.

McPherron, R. L., Baker, D. N., Bargatze, L. F., Clauer, C. R., and Holzer, R. E.: IMF control of geomagnetic activity, Adv. Space Res., 8(9), 71-86, 1988.

Moen, J. and Brekke, A.: The solar flux influence on quiet time conductances in the auroral ionosphere, Geophys. Res. Lett., 20, 971-974, 1993 
Newell, P. T., Sotirelis, T., Liou, K., Meng, C.-I., and Rich, F. J.: A nearly universal solar wind-magnetosphere coupling function inferred from 10 magnetospheric state variables, J. Geophys. Res., 112, A01206, doi:10.1029/2006JA012015, 2007.

Nishida, A.: DP 2 and polar substorms, Planet. Space. Sci., 19, 205-221, 1971.

Obayashi, T. and Nishida, A.: Large-scale electric field in the magnetosphere, Space. Sci. Rev., 8, 3-31, 1968.

Perreault, W. K. and Akasofu, S.-I.: A study of geomagnetic storms, Geophys. J. R. Astron. Soc., 54, 547-573, 1978.

Ruohoniemi, J. M. and Greenwald, R. A.: The response of highlatitude convection to a sudden southward IMF turning, Geophys. Res. Lett., 25, 2913-2916, 1998.

Rostoker, G.: Geomagnetic indices, Rev. Geophys. Space Phys., 10, 935-950, 1972.

Rostoker, G., Winningham, J. D., Kawasaki, K., Burrows, J. R., and Hughes, T. J.: Energetic Particle Precipitation into the HighLatitude Ionosphere and the Auroral Electrojets, 2. Eastward Electrojet and Field-Aligned Current Flow at the Dusk Meridian, J. Geophys. Res., 84(A5), 2006-2018, 1979.
Rostoker, G., Akasofu, S.-I., Foster, J., Greenwald, R. A., Kamide, Y., Kawasaki, K., Lui, A. T. Y., McPherron, R. L., and Russell, C. T.: Magnetospheric substorms - Definition and signatures, J. Geophys. Res., 85, 1663-1668, 1980.

Rostoker, G., Savoie, D., and Phan, T. D.: Response of magnetosphere-ionosphere current systems to changes in the interplanetary magnetic field, J. Geophys. Res., 93(A8), 633-8641, 1988.

Vasyliunas, V. M.: Mathematical models of magnetospheric convection and its coupling to the ionosphere, in: Particles and Fields in the Magnetosphere, edited by: McCormac, B. M., pp. 60-71, D. Reidel, Hingham, Mass., 1970.

Weimer, D.: Substorm time constants, J. Geophys. Res., 99(A6), 11005-11015, 1994.

Weimer, D. R., Ober, D. M., Maynard, N. C., Collier, M. R., McComas, D. J., Ness, N. F., Smith, C. W., and Watermann, J.: Predicting interplanetary magnetic field (IMF) propagation delay times using the minimum variance technique, J. Geophys. Res., 108, A1, doi:10.1029/2002JA009405, 2003. 